\title{
EURECA-PRO: The European University on Responsible Consumption and Production
}

\author{
Lisa Pichler', Jasmin Egger ${ }^{1}$, Susanne Feiel ${ }^{1,2}$, Volkmar Kircher², and Agnieszka Kosciuszko \\ ${ }^{1}$ Montanuniversität International Relations Office-EURECA-PRO, Montanuniversität Leoben, Leoben, Austria \\ ${ }^{2}$ Resources Innovation Center Leoben, Montanuniversität Leoben, Leoben, Austria
}

Received August 6, 2021; accepted August 19, 2021; published online September 16, 2021

\begin{abstract}
The European Commission (EC) called for proposals to form European University Alliances (EUA) in 2019 and 2020 to promote Europe's universities competitiveness in the world and strengthen the European Higher Education Area (EHEA) and European Research Area (ERA). With the objective to create a global educational core hub on Sustainable Development Goal (SDG) 12 “responsible consumption and production", a consortium of seven universities, led by Montanuniversität Leoben, received a threeyear funding in 2020 for the development of a European University on REsponsible Consumption And PROduction (EURECA-PRO).
\end{abstract}

Keywords: Sustainable Development, Responsible consumption and production, Responsible Material Flows, European Universities, European Higher Education Area, European Research Area, SDG 12

EURECA-PRO: Die Europäische Universität für verantwortungsvollen Konsum und verantwortungsvolle Produktion

Zusammenfassung: Die Europäische Kommission hat 2019 und 2020 zur Einreichung von Anträgen zum Aufbau von Europäischen Universitäten Allianzen aufgefordert, um die Wettbewerbsfähigkeit europäischer Universitäten zu fördern und den europäischen Hochschulraum (EHEA) sowie den europäischen Forschungsraum (ERA) zu stärken. Die Montanuniversität Leoben hat 2020 den Zuschlag für eine 3-Jahres Finanzierung erhalten und führt nun ein Konsortium von sieben europäischen Universitäten an, welches die European University on REsponsible Consumption And PROduction (EURECA-PRO) entwickelt. EURECA-PRO hat sich zum Ziel gesetzt, das globale Bildungszentrum im

MMag. L. Pichler ( $\bowtie)$

Montanuniversität International Relations Office-EURECA-PRO,

Montanuniversität Leoben,

Franz-Josef-Straße 18,

8700 Leoben, Austria

lisa.pichler@unileoben.ac.at
Bereich des nachhaltigen Entwicklungsziels 12 „verantwortungsvoller Konsum und Produktion“ zu werden.

Schlüsselwörter: Nachhaltige Entwicklung, Verantwortungsvoller Konsum und Produktion, Verantwortungsvolle Materialflüsse, Europäische Universitäten, Europäischer Hochschulraum, Europäischer Forschungsraum, SDG 12

\section{European University Alliances: Creating and Enabling Environment to Unlock the Full Potential of European Universities}

The EC seeks to foster European universities' global competitiveness, to ensure excellence in teaching and research, without compromising on inclusiveness and diversity and of course keeping up universities' autonomy and freedom. 41 EUAs (17 from the first call in 2019, 24 from the 2 nd call in 2020) [1] are currently acting as testbeds for the transformation of the EHEA, funded by the Erasmus+ programme of the European Union for three years each. Around $5 \%$ of all higher education institutions (HEls) of Europe are involved in an alliance (more than 280 out of about 5000 European HEls [2]) and are experiencing and testing a deeper collaboration between the institutions. The alliances are invited to create joint European degrees, policy frameworks across Europe that facilitate seamless transnational cooperation, and automatic recognition processes as well as to increase the physical and virtual mobilities of students and staff. The initiative faces a lot of bureaucratic hurdles along the way as regulations differ from country to country. The hardest part lies in finding agreements between the partners of the alliance that are, at the same time, in line with national regulations in each country as several universities of one country are part of different alliances and as such are connected to other countries and their respective regulations. Best practice examples to overcome red tape shall be replicated in the future by other universities. 


\section{EURECA-PRO: The European University on Responsible Consumption and Production}

The alliance EURECA-PRO is led by Montanuniversität Leoben with six partners from Germany, Greece, Poland, Spain and Romania. The consortium consists of four technical universities (Montanuniversität Leoben, Technische Universität Bergakademie Freiberg, Silesian University of Technology, Technical University of Crete), two comprehensive universities (University of León, University of Petrosani) and one University of Applied Sciences (Hochschule Mittweida). In total, the consortium serves 54,500 students, employs 9400 researchers and administrative staff and is organised in 60 departments.

Altogether 25 associated partners (public bodies, media institutions, student networks, industry organisations, foundations, enterprises, NGOs, governing bodies, research and education centres, and other HEls) are supporting EURECA-PRO. The topic of responsible consumption and production attracts a lot of people, and EURECA-PRO is constantly expanding its network.

The twofold and long-term vision followed in EURECAPRO sets the target at becoming a global educational core hub and interdisciplinary Research \& Innovation leader in qualitative environmental and social framework development for responsible consumption and production of resources and goods in 2040. EURECA-PRO promotes the effective transformation of the European higher education system into a more inclusive and borderless system to ensure greater academic freedom, free mobility, civic engagement, equal participation, and transparent joint governance, as well as the development of shared fundamental philosophies, common values, and solution-oriented approaches towards social cohesion, responsible citizenship and humanhood, and a responsible system design.

\subsection{EURECA-PRO's Joint Studies on Responsible Consumption and Production}

The alliance defines education as an agent of change for global sustainability challenges and fundamental societal transformation. Striving for inclusive, borderless, and integrated European education, EURECA-PRO wants to generate competent and well-prepared graduates who, as the top experts of the future, can contribute to a better European society and solve humankind's current challenges. EURECAPRO also takes measures to foster the social dimension of learning, lifelong learning, and equal excellent education in line with SDG4 "quality education". System and context-oriented, interdisciplinary approaches ensure that EURECA-PRO students grasp the complexity of the challenges so that solutions can be generated through working together across fields of expertise and borders. EURECAPRO is strongly convinced that close interactions and synergies between technological, environmental, economic, legal, and societal aspects are necessary to succeed and transform this complex system of interdependencies.
The alliance offers a unique mix of top-level cross-disciplinary education and research that enables students and staff to focus on many different fields from multiple perspectives. It is believed that engineer who understands a legal framework, an economist who understands consumer behaviour and a sociologist who understands technical challenges will have an advantage as researchers and employees on the European and global labour market.

Within the first three years of the project, the European Studies on Responsible Consumption and Production (EStRCP) will be developed for the three study cycles (Bachelor, Masters, and PhD). PhD studies will be implemented in October 2021, Master and Bachelor Studies in October 2023 the latest.

Flexible study programmes incorporating novel teaching techniques, such as Project-Based Learning, distance and blended learning, will be cross-disciplinary and available as full- or part-time studies. An interdisciplinary approach is a crucial component of the studies as the project partners are both technical and comprehensive HEls.

Students can design their own tracks and select their majors and even chose their preferred teaching language on many occasions. It further brings them to numerous partner institutions: As a prerequisite, students must select courses that are spread over at least three to four different institutions to ensure mobility and in-depth cultural understanding. All this leads to a wide variety of graduates across different disciplines. Students will have a wide understanding of the system complexities and general understanding of the associated inter-disciplines, but every student also has a very deep specialisation of their own. Additionally, integration of transversal skills into education structures ensures a cohesive understanding of social responsibility.

To provide an inclusive access, a Supplementary European Studies Module (SuppIESt) is designed for Bachelor's degree students from any university that can serve as an all-inclusive gateway to the Master's programme. All partners will offer this module for the students of their other programmes and their mobility students, so they can reorient themselves if they decide to turn towards European Studies programmes.

The alliance successfully implemented the 14-lectures series "Responsible Consumption and Production" during the summer semester of 2021 and partnered in "Digital CirCOOL-The Aluminium Cycle" summer school. In the winter semester 2021, EURECA-PRO, together with the UNESCO Competence Centre of Mining Engineering Education Austrian Branch, will organise the lecture series "Planetary Boundaries", which is open to all and will be presented by globally renowned experts.

EURECA-PRO is specialized in utilizing Innovative Pedagogic Methodologies and Educational Tools in the classroom. Additionally, the state-of-the-art expertise in problem-based teaching is specifically applied. Digital tools, such as augmented and virtual reality, will be applied with efficient contributions of existing partner frameworks. 


\subsection{EURECA-PRO Innovation, Joint Research, and Lighthouse Missions}

Innovation and research are the basis for the ongoing green and digital transformations. Within EURECA-PRO research focuses on SDG12, which calls for decoupling economic growth from unsustainable resource use and emissions and improving the management of hazardous substances and waste. In particular, it calls for implementation of the 10-Year Framework of Programmes on Sustainable Consumption and Production, for efficient use of natural resources, for cutting food and other waste, for responsible management of chemicals, for sustainable public procurement, and for companies to adopt more sustainable practices [3].

This holistic approach of SDG12 covers also crucial topics related to Planetary Boundaries and the ambitious European Green Deal targets, reducing the EU's net greenhouse gas emissions by at least $55 \%$ by 2030 compared to 1990 and being the first climate neutral continent by 2050 [4]

EURECA-PRO combines the strengths of seven universities: technical, comprehensive and a university of applied sciences, to cover the whole value chain and the systemic dimensions of economy, ecology, technology as well as social- policy- and legal- aspects. The consortium has the vision of "circular responsible consumption and production". Due to this sophisticated interdisciplinary knowledge distribution, it is possible to realise research projects around the value chain (Fig. 1): From exploration of primary raw materials, via mining and processing, to responsible production, the private consumer as well as industrial consumption, environmental protection and finally recycling-which closes the loop [5].
EURECA-PRO's internationality and interdisciplinarity follows the idea of the new ERA launched in 2020, by strengthening mobility of researchers and free flow of knowledge and technology through greater cooperation among our HEls, by advancing our talents, skills and careers across scientific sectors and disciplines, by improving access to excellence for researchers across the EU via open access publishing and a planned open repository as well as by open science practices to raise awareness on responsible consumption and production [6].

For the joint EURECA-PRO research activities, an organisational Scientific Framework Charter (SFC) was developed which determines the mode of joint interuniversity research collaboration.

A comprehensive inventory of SDG12-related publications and projects of all partner HEls is currently being conducted, which will reveal the extensive knowledge but also possible research gaps that need to be filled. Fig. 2 shows the current status of the inventory with regard to the SDG12 research topics that can be assigned to projects.

At the time of publication, a total of 611 SDG12 research topics have been identified and addressed in projects. Clustering the data will result in lighthouse research concepts regarding sustainable consumption and production in all relevant disciplines and cross-institutional research groups. Each participating university focuses on their expertise areas to achieve complementarity and an enhanced level of interdisciplinary research results. Society and industry are actively involved in the knowledge creation process through designated events and discussion fora as well as online discourse. This enables the research groups to apply real-life challenges in the definition and implementation of Lighthouse Research Missions (LH) in all

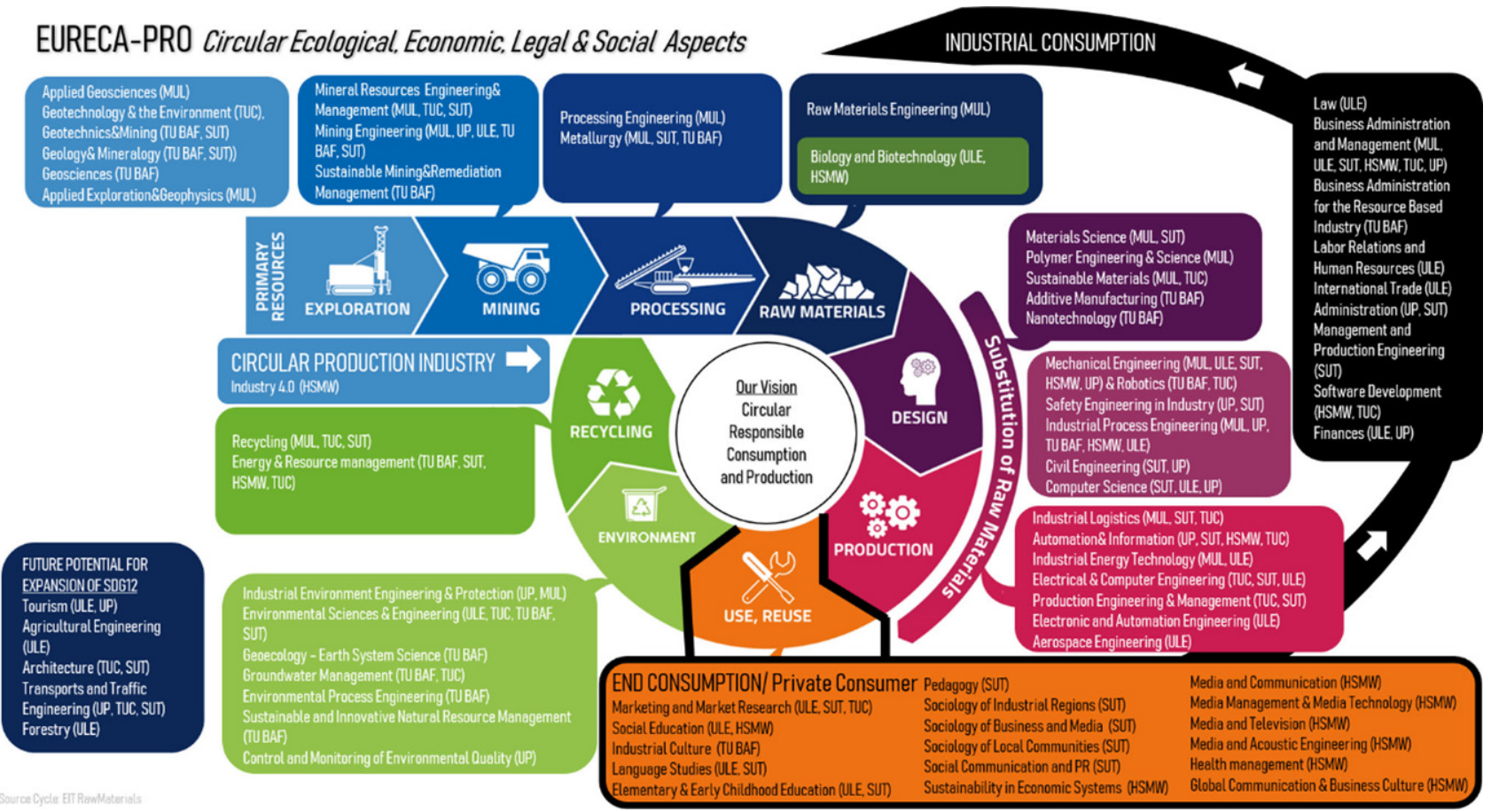

Fig. 1: Competencies and research fields of EURECA-PRO [5] 
relevant disciplines and cross-institutional research groups already yield promising research results that flow into the practical education of the European Studies programme via Problem-Based Learning (PBL). As strengthening aspect for the lighthouse missions, complimentary external expertise partnerships with international industry organizations, research institutions, NGOs and other relevant associated organisations are forged, and a Global Partner and Competence Index (GPCl) will be developed.

In addition, Open Science Awareness Events to form close ties and exchange with civic society and industry community are hold biannually.

\subsection{Celebrating Europe's Uniqueness: Languages and Cultures}

The knowledge about our common European heritage and the understanding of cultural differences and values are key, interdisciplinary skills for successful cooperation. EURECA-PRO highlights the diversity within the alliance by offering language and cultural courses in all the consortium's languages: German, Spanish, Polish, Romanian, and Greek.

Ranging from the North of Germany to Southern Europe with allied partners in Greece and Spain, or spreading to Eastern Europe in central Romania: aside from languages - the customs, traditions and habits in the alliance's countries could not be more diverse. Through workshops on cultural awareness and sensitivity, educational offers on European identity as well as communication skills, the benefits of working in a multicultural group are highlighted for both students and staff.

Mobility is a natural and logical extension of language learning, of the desire to understand European culture and to truly become a European citizen. Within EURECA-PRO students can choose in which countries to study or which semesters they wish to study abroad. However, they also have the possibility to choose alternative forms for learning experiences in foreign countries such as a short stay abroad, summer schools, or offers that combine a stay abroad with a virtual component. In addition to students, all staff (teaching and administrative) are encouraged to pursue training opportunities abroad and to intensify international cooperation.

\subsection{EURECA-PRO's Joint Virtual Campus}

Each participating university brings in its own expertise to take over the activities necessary to cover the entire spectrum of what is needed to realise the vision: expertise in the value life cycle of material flows as well as the associated humanistic, legal, economic, sociological and cultural disciplines to complete the entire systemic picture of responsible consumption and production.

To facilitate the exchange between the institutions, their students, academic and administrative staff as well as their regional societies, EURECA-PRO currently implements a digital main platform with thematically relevant sub-branches constituting a virtual campus. Education, research, administration, transversal skills, entrepreneurship training, and the outreach to society will be supported by highly modern virtual means. In the long run, the virtual campus will evolve to a vivid platform of exchange and knowledge transfer-among students and researchers and also at a community and regional scale.

The platforms will also offer space for virtual language training, co-teaching training (where teachers work in pairs with teachers from partner institutions), digital skills training, STEM (Science, Technology, Engineering, Mathematics) training, soft skills coaching, or European identity awareness challenges.

\subsection{EURECA-PRO and the Formation of a Legal Entity}

With six different legal systems and regulations regarding the education system, extensive knowledge and an excellent understanding of education law and national regulations is required. A four-stage governance system until 2040 meets the changing needs of EURECA-PRO as it evolves and ensures the long-term sustainability of the al-
Fig. 2: Inventory of SGD12 related research projects of the EURECA-PRO consortium

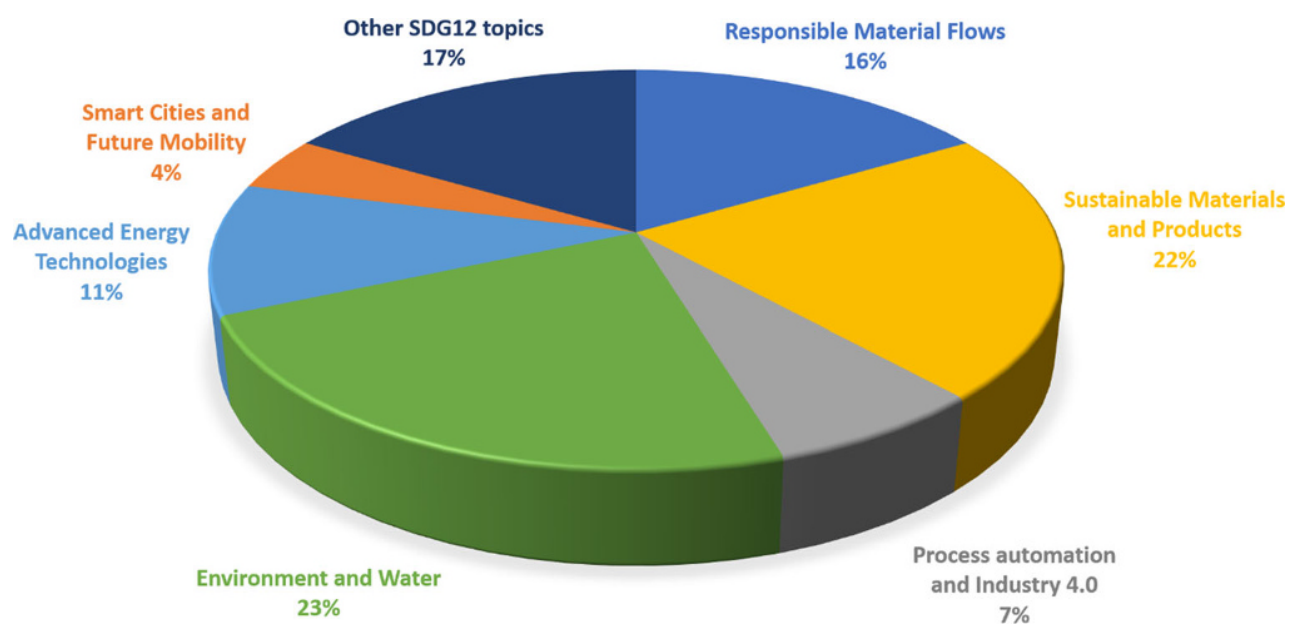


liance. In governance Phase I, until 2023, all the partners contribute by seconding staff and students to EURECAPRO's boards and co-creation groups, such as the StudentCentred Co-Creation Group, the Research Task Force, the Education Council, and other participatory groups. These groups will establish frameworks for the new European Studies Portfolio, research, and transversal skills structures and their respective administrative aspects. The establishment of a joint admission process and the development of an automatic recognition system is also a goal during this first project phase. Concerning project management one person per institution leads one work package to ensure equal participation.

By 2023, Governance Phase I "Charting the way towards 2040" will be successfully implemented and will result in a strong cross-institutional foundation. The governance structure of the European University and all its affiliated groups will enable competent joint working and decisionmaking and allow taking action.

Financial opportunities for EURECA-PRO will be explored as sustainable funding is key for the success of this initiative. As a first measure of exploitation, a successful Horizon 2020 project proposal was submitted and is starting in September 2021 (RE-EURECA-PRO-the research dimension of EURECA-PRO). It will strengthen the research and innovation dimension and thus the transformative potential of the EURECA-PRO alliance.

\subsection{Dissemination of EURECA-PRO's Results: Sustainability and EURECA-PRO's Third Mission}

Bringing the benefits and knowledge of EURECA-PRO's activities to the universities' ecosystem means translating scientific findings into the everyday life of the citizens, students, staff, companies, and respective regions covered by the alliance.

Therefore, EURECA-PRO publishes Open Access, promotes and hosts Open Science Awareness Events, uses social media channels, creates short videos on scientific findings, and runs the EURECA-PRO website (www.eurecapro. eu) to raise awareness on responsible consumption and production in a civic society and in the industry community.

\section{Conclusion}

EURECA-PRO is aiming to bring together a new generation of creative Europeans able to cooperate across languages, borders, and disciplines to address societal challenges and skills shortages faced in Europe. The allied universities jointly cover the whole spectrum of SDG12 "responsible consumption and production" and they will develop a thorough complimentary and well-balanced cross-skill, crosssector, cross-discipline and cross-culture innovative education and research programme with the result of a wellrounded new and effective way of approaching higher education, as a supra institution covering wide regions of the
EU and bringing out responsible future citizens who can tackle the most pressing challenges of humankind today.

Education, Research, Innovation, and Transversal Skills are the key pillars of EURECA-PRO's work packages paired with a well thought through governance structure for the consortium, a dedicated Third Mission to benefit society and dissemination activities to create an enthusiastic community.

As European Commission states: Education and training will be a key driving force for achieving a recovery geared on the Green and Digital transitions. Furthermore, work on the European Education Area will help contribute to the geopolitical positioning of the EU and its Member States [2].

Acknowledgements. The authors acknowledge the financial contribution of Erasmus+ program, Contract No. 101004049

Funding. Open access funding provided by Montanuniversität Leoben.

Open Access This article is licensed under a Creative Commons Attribu tion 4.0 International License, which permits use, sharing, adaptation, distribution and reproduction in any medium or format, as long as you give appropriate credit to the original author(s) and the source, provide a link to the Creative Commons licence, and indicate if changes were made. The images or other third party material in this article are included in the article's Creative Commons licence, unless indicated otherwise in a credit line to the material. If material is not included in the article's Creative Commons licence and your intended use is not permitted by statutory regulation or exceeds the permitted use, you will need to obtain permission directly from the copyright holder. To view a copy of this licence, visit http://creativecommons.org/licenses/by/4.0/.

\section{References}

1. European Commission: Education and Training, European Universities Initiative, https://ec.europa.eu/education/education-in-theeu/european-education-area/european-universities-initiative en (04.08.2021)

2. European Commission: Communication from the Commission of the European Parliament, the Council, the European Economic and Social Committee and the Committee of the Regions on achieving the European Education Area by 2025, COM(2020) 625 final, Brussels, 2020, https://ec.europa.eu/education/sites/default/files/ document-library-docs/communication-european-education-area. pdf (04.08.2021)

3. Chan, S.; Weitz, N.; Persson, Å.; Trimmer, C.: SDG 12: Responsible Consumption and Production. A Review of Research Needs. Technical annex to the Formas report Forskning för Agenda 2030: Översikt av forskningsbehov och vägar framåt, Stockholm Environment Institute, Stockholm, 2018

4. European Commission, Communication from the Commission to the European Parliament, the Council, the European Economic and Social Committee and the Committee of Regions 'Fit for 55': delivering the EU's 2030 Climate Target on the way to climate neutrality, $\operatorname{COM}(2021) 550$ final, Brussels, 2021, pp 1-14

5. Moser, P.; Feiel, S.; Barbknecht, K-D.; Diamadopoulos, E.; Mężyk, A.; Baelo, R.; Radu, S. M.; Hilmer, L.; Komnitsas, K.: EURECA-PRO, The European University Alliance on Responsible Consumption and Production. Proceedings of the European Metallurgical Conference EMC 2021, 2021

6. Directorate-General for Research and Innovation (European Commission): A new European Research Area. Based on excellence. Competitive, talent-driven and open, Publications Office of the European Union, Luxembourg, 01.10.2020. PDF: ISBN 978-92-7622302-3, https://doi.org/10.2777/11151, KI-02-20-753-EN-N

Publisher's Note. Springer Nature remains neutral with regard to jurisdictional claims in published maps and institutional affiliations. 